\title{
Variations in aerologically derived Arctic precipitation and snowfall
}

\author{
Mark C. Serreze, Mark C. Rehder, Roger G. Barry, \\ Cooperative Institute for Research in Environmental Sciences, University of Colorado, Boulder, CO 80309, U.S.A. \\ JOHN E. WALSH, \\ Department of Atmospheric Sciences, University of Illinois-Urbana-Champaign, Urbana, IL 61801, U.S.A.
}

DAVID A. Robinson

Department of Geography, Rutgers University, New Brunswick, NJ 08903, U.S.A.

\begin{abstract}
Data from a rawinsonde network are used to provide aerological estimates of monthly precipitation minus evaporation $(P-E)$ averaged over the region north of $70^{\circ} \mathrm{N}$. Using published climatological estimates of $E$, area-averaged $P$ is obtained for each month and year as a residual. Using surface temperatures from the rawinsonde network, the fraction of precipitation falling as snow is then estimated. Over the 197491 study period, precipitation and snowfall (water equivalent) have annual means of 26.6 and $19.0 \mathrm{~cm}$, respectively. Assuming a representative aged snow pack density of $330 \mathrm{~kg} \mathrm{~m}^{-3}$ yields a total snow depth of $57.5 \mathrm{~cm}$. The mean annual cycles of both variables display an autumn maximum, but because of the temperature dependency, nearly all precipitation falls as rain during July and August. Composite analyses reveal that increased precipitation for all seasons and increased snowfall for winter and autumn are favored by a "winter-type" circulation pattern, characterized by stronger troughs over the Atlantic and Eurasian sectors of the Arctic, associated with increased cyclonic activity over the Arctic peripheral seas.
\end{abstract}

\section{INTRODUCTION}

Increasing recognition of the importance of the Arctic in the global climate system points to the need for improved assessments of Arctic precipitation and snowfall. The existence of the ice cover strongly depends on the maintenance of a relatively fresh low-density surface layer, driven primarily by precipitation over land and subsequent fresh-water inflow by rivers, but also by precipitation over sea-ice and open-water areas, and summer melt (Aagaard and Carmack, 1989). A significant contributory factor is the high surface albedo of the ice cover which, when fully snow-covered in May, may exceed 80\% (Robinson and others, 1992). Nevertheless, the characteristics of Arctic precipitation and snowfall are poorly known. Over the Arctic Ocean (Fig. 1) direct information is largely limited to field measurements of snow depth (e.g. Romanov, 1993). Although records are available for coastal, island and inland stations (Vose and others, 1992), the tendency for collection gauges to "catch" only a fraction of snow in areas where wind-driven snow is common results in a bias towards low precipitation amounts (Woo and others, 1983). As most Arctic stations are at low altitude, the tendency for precipitation to increase with elevation probably also results in an underestimate of

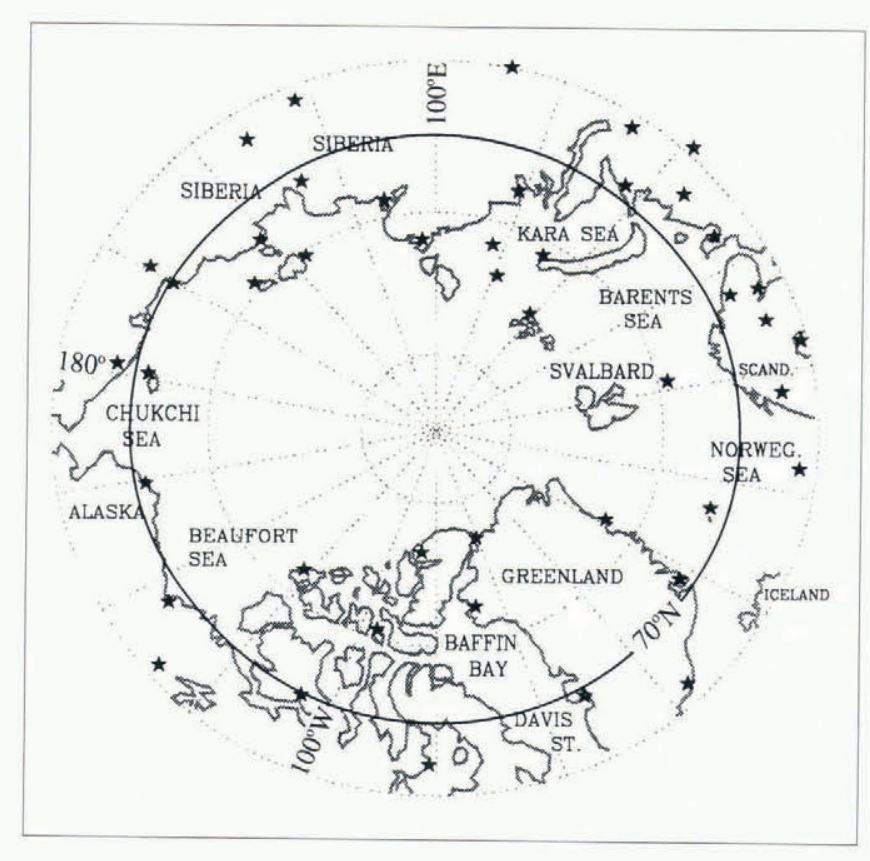

Fig. 1. Location map showing the rawinsonde stations used in the analysis (stars). Results from several approximately co-located stations have been combined to provide complete records (see lext). The $70^{\circ} \mathrm{N}$ circle is shown in bold. 
regional averages. These problems are reviewed by Groisman and others (1991).

Recently, we have begun to address some of these concerns through providing areal estimates of precipitation minus evaporation $(P-E)$ via the water-vapor flux convergence approach (Alestalo, 1983), using an extensive rawinsonde archive. $P-E$ represents the net freshening or salination of the ocean through surface exchanges with the atmosphere, and the net gain or loss of water by the land surface through exchanges with the atmosphere. Serreze and others (in press) used rawinsonde data for 197491 to determine climatological $P-E$ for the region north of $70^{\circ}$ N. $P-E$ is positive in all months, peaking in September. The annual value of $16.3 \mathrm{~cm}$ is $36 \%$ higher than the estimate of Peixoto and Oort (1992) based on earlier data. In a subsequent study, Walsh and others (1994) examined inter-annual variations in $P-E$ for a smaller central Arctic Ocean domain and the Mackenzie River basin.

Here, we extend these studies and use published climatological estimates of $E$ to obtain $P$ as a residual over the region north of $70^{\circ} \mathrm{N}$ for each month and year from 1974 to 1991. Using a linear temperature adjustment (Ross and Walsh, 1987), we then estimate the fraction of $P$ represented by snow $(S)$, with interannual variations in $P$ and $S$ diagnosed in terms of circulation. Comparisons are made with precipitation values redigitized for the same domain from the Gorshkov (1983) atlas, based on Soviet data up to 1980; the Maykut and Untersteiner (1971) snowfall climatology; and the April snow-depth maps provided by Romanov (1993), based on Russian expeditions and field programs in the 1970 s and 1980 s. The choice of the $70^{\circ} \mathrm{N}$ circle for the $P-E$ computations reflects the relatively dense station network near this latitude (Fig. 1), as well as the desire for consistency with previous work. Objective analyses produced by numerical weather centers may eventually be able to provide accurate Arctic precipitation data sets (Chahine, 1992), and planned "reanalysis" projects will allow the fields to be used more effectively in vapor-flux computations. Nevertheless, at present, analysis of rawinsonde data is still the best approach for assessing atmospheric hydrological variations.

\section{DATA AND TECHNIQUES}

\section{a. Rawinsonde archive}

Our primary data base is the historical Arctic rawinsonde archive (HARA) (Kahl and others, 1992), which contains all available soundings for fixed stations north of $65^{\circ} \mathrm{N}$ through 1991. Soundings typically extend to at least 300 mbar and contain reports at fixed mandatory pressure levels (e.g. surface, 850 and 500 mbar) and significant levels (irregular pressure levels reported on the basis of conventional vertical-change criteria). Unfortunately, the number of significant levels reported for Eurasian stations is reduced prior to 1974 . As the lack of significant levels may degrade the accuracy of the moisture calculations, we use data for the 1974-91 period only, at both 0000 and 1200 UTC.

\section{b. Estimation of $P-E$}

Quality control and data reduction follow Serreze and others (in press). In that study, for each station and year represented in the HARA, monthly means were compiled of the vertically integrated specific humidity $(Q$, usually termed precipitable water) and meridional vapor flux $(F)$ from the surface to $300 \mathrm{mbar}$, above which we assume water vapor to be negligible. The mean station fluxes were then passed into a Cressman (1959) analysis to interpolate the data to $70^{\circ} \mathrm{N}$ at every $10^{\circ}$ of longitude. The vapor-flux convergence for each month was determined as

$$
-V \cdot F_{\mathrm{L}}=1 / A \oint F_{\mathrm{L}} \mathrm{d} C
$$

where $F_{\mathrm{L}}$ is the interpolated flux at a given longitude, $\mathrm{d} C$ is the length along the $70^{\circ} \mathrm{N}$ latitude circle (totaling $\left.1.37 \times 10^{4} \mathrm{~km}\right)$, and $A$ is the area enclosed $\left(15.4 \times 10^{6}\right.$ $\left.\mathrm{km}^{2}\right)$. Following Alestalo (1983), the flux convergence was then used to estimate monthly $P-E$ for the region north of $70^{\circ} \mathrm{N}$ as

$$
P-E=-\nabla \cdot F_{\mathrm{L}}-\partial Q / \partial t
$$

where $\partial Q / \partial t$ is the monthly rate of change of precipitable water in the domain. This approach ignores the contribution of condensed water (as either ice crystals or droplets), which, especially for the Arctic, should be negligible.

Serreze and others (1994) ignored changes in the distribution of stations; any individual station mean was passed into the interpolation procedure, provided that it was represented by a required minimum number of cases. Results for the 18 years (1974-91) were then averaged. Walsh and others (1994) find that minor changes in the station network have little impact on analysis of interannual variations in $P-E$. Nevertheless, to provide a homogeneous data base, we first examined the monthly means for each station and year. If these failed to pass the threshold requirement for the number of cases, they were treated as missing, with new monthly means then found by Cressman interpolation from surrounding station means. This resulted in complete time series for all stations. $P-E$ was then determined using monthly means only from those stations requiring interpolation from surrounding stations for less than 30 of the possible 216 months in the 18 year data record $(13.8 \%)$. Following Serreze and others (in press), $\partial Q / \partial t$ for each month $(m)$ was found from the difference in $Q$ averaged over month $(m)$ and $(m+1)$, minus the average over month $(m)$ and $(m-1)$, using only those stations north of $70^{\circ} \mathrm{N}$. The final network of 47 selected stations is shown in Figure 1. Partial records for several nearly co-located stations have been combined.

\section{c. Estimation of precipitation and snowfall}

The Korzun (1977) atlas contains climatological monthly estimates of $E$ for different regions of the Arctic, based on coastal and drifting stations. Using these data, climatological monthly $E$ was obtained for the region north of 
$70^{\circ} \mathrm{N}$. The monthly totals, which range from $0.30 \mathrm{~cm}$ in January to $2.05 \mathrm{~cm}$ in October (with an annual total of $10.3 \mathrm{~cm}$ ), were then substituted into the $P-E$ estimates to obtain $P$ for each month and year. $P$ is hence only solved in terms of a climatological seasonal cycle in $E$; our resulting $P$ values will still contain some unresolved component of $E$ related to its inter-annual variability. If direct measurements of $P$ and $E$ revealed that the two variables are negatively (positively) correlated, substitution of climatological $E$ into our $P-E$ values would act to overestimate (underestimate) the true inter-annual variability in $P$. Although an inverse relationship seems more likely (i.e., with high $P$ one might expect a smaller vapor gradient, leading to a reduction in $E$ ), the strong additional dependence of $E$ on the gradient in wind speed makes this difficult to assess. Although it may have been possible to use the rawinsonde network to provide time series of $E$, we made no attempt to do so here.

Following Ross and Walsh (1987), the fraction of precipitation falling as snow was assumed to vary linearly from $100 \%$ for an air temperature $<-5^{\circ} \mathrm{C}$ to $0 \%$ for $3^{\circ} \mathrm{C}$. The temperature $(T)$ data consisted of the aggregate monthly means for each year of the lowest reported temperature level in the soundings, using all stations north of $70^{\circ} \mathrm{N}$. Clearly, this approach also has limitations. Although during the cold season it is reasonable to expect nearly all precipitation over the Arctic basin to fall as snow, the inland and coastal distribution of the stations may result in basin-wide temperatures being somewhat overestimated, potentially leading to underestimates of snowfall during summer and the transition months. Furthermore, as the temperature on "precipitation days" during summer is likely to be lower than the mean monthly temperature, this will also act to underestimate snowfall. It should be clear that we are providing first-order estimates of $P$ and $S$.

\section{RESULTS}

\section{a. Long-term means}

Averaged over the 18 years, annual $P-E, P$ and $S$, all expressed in terms of water equivalent (w.e.), averaged over the $70-90^{\circ} \mathrm{N}$ region, are $16.3,26.6$ and $19.0 \mathrm{~cm}$, respectively. The $P-E$ estimate is identical to that of Serreze and others (in press). By comparison, annual $P$ from the Gorshkov (1983) atlas is slightly higher at $29.3 \mathrm{~cm}$. Using the same mean snowpack density of $330 \mathrm{~kg} \mathrm{~m}^{-3}$ employed by Maykut and Untersteiner (1971), which accounts for settling and aging of the accumulated snowpack (typical fresh snowfall densities are $70-165 \mathrm{~kg} \mathrm{~m}^{-3}$; see Goodison and Metcalfe, 1981), the w.e. snowfall equates to an accumulated snow depth of $57.9 \mathrm{~cm}$. The Maykut and Untersteiner (1971) climatology, which is used as the basis for snow-cover input in most current sea-ice models, has an accumulated annual snow depth of $40.0 \mathrm{~cm}$. As that estimate is representative of the sea-ice-covered regions of the Arctic, and ours includes oceanic regions over the Atlantic side of the Arctic where precipitation appears to be comparatively high (Gorshkov, 1983), this difference is not surprising.

Figure 2 provides the seasonal cycles in $P, S$ and $T$.

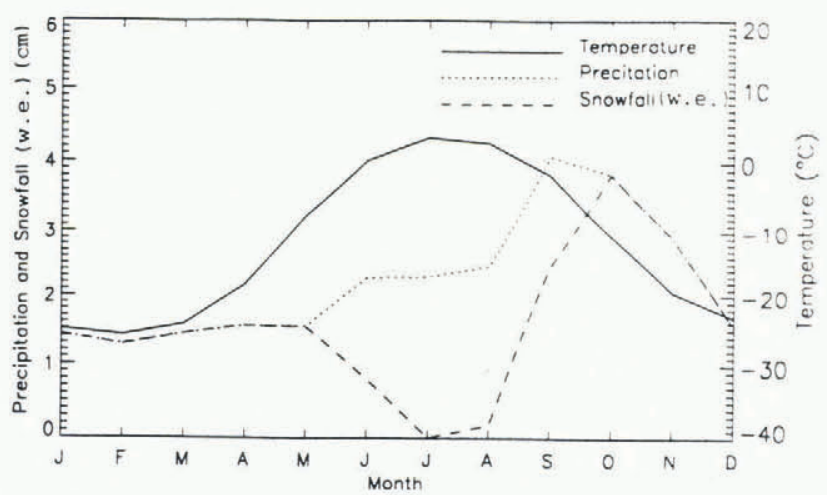

Fig. 2. Seasonal cycle of mean aerologically derived precipitation $(\mathrm{cm})$, snowfall (cmw.e.) and temperature $\left({ }^{\circ} \mathrm{C}\right)$.

From October through May, $P$ and $S$ are identical, reflecting the mean temperatures $<-5 \mathrm{C}$. By contrast, essentially all precipitation falls as rain during July and August. Both variables show a September-November maximum. Monthly precipitation from the Gorshkov (1983) atlas is $2.2 \mathrm{~cm}$ in January, $1.6 \mathrm{~cm}$ in April, $3.8 \mathrm{~cm}$ in August and $2.0 \mathrm{~cm}$ in December. Gorshkov's values are hence somewhat higher during winter months with a somewhat lower maximum occurring earlier in the year. Maykut and Untersteiner (1971) show a late AugustOctober snowfall maximum. Their maximum monthly snowfall w.e. of $4.3 \mathrm{~cm}$ is reasonably close to our October maximum of $3.8 \mathrm{~cm}$. Romanov's (1993) average central Arctic snow depth of $20 \mathrm{~cm}$ for April is only one-third of the density-adjusted accumulated September-April snowfall from Figure 2. Again, given our larger domain, this is not surprising.

\section{b. Inter-annual variations}

Figures 3 and 4 display the time series of $P$ and $S$ as bar plots. For each year, the total length of the bar represents the annual total, while from bottom to top the individual bar segments represent the contributions from winter (January-March), spring (April-June), summer July-

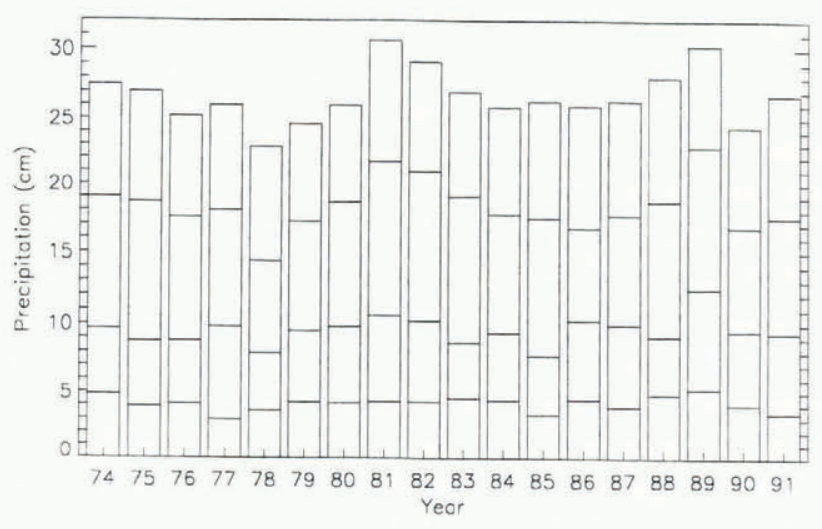

Fig. 3. Annual and seasonal time series of aerologically derived precipitation $(\mathrm{cm})$. From bottom to top, the individual bar segments for each year represent winter, spring, summer and autumn, respectively. The long-term seasonal means are: winter $(4.1 \mathrm{~cm})$; spring $(5.4 \mathrm{~cm})$; summer $(8.8 \mathrm{~cm})$; autumn $(8.3 \mathrm{~cm})$. 


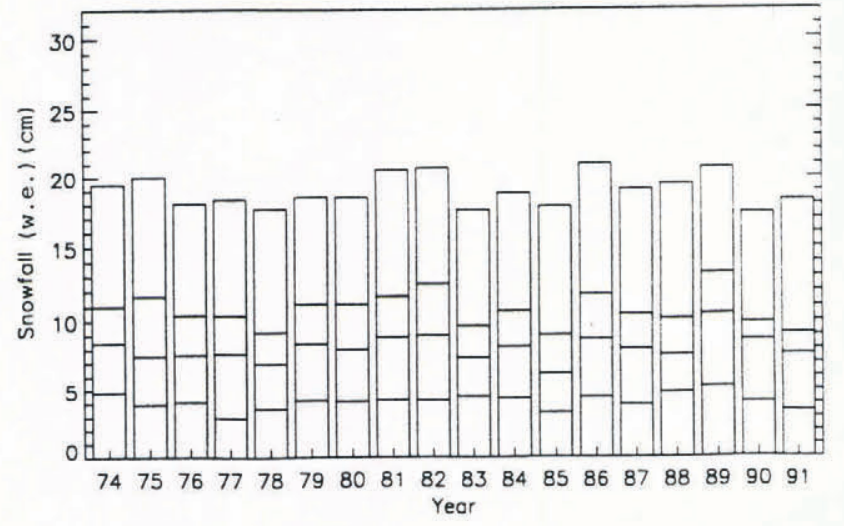

Fig. 4. Annual and seasonal time series of aerologically derived snowfall ( $\mathrm{cm}$ w.e.). From bottom to top, the individual bar segments for each year represent winter, spring, summer and autumn, respectively. The long-term seasonal means are: winter $(4.1 \mathrm{~cm})$; spring $(3.9 \mathrm{~cm})$; summer $(2.6 \mathrm{~cm})$; autumn $(8.3 \mathrm{~cm})$.

September) and autumn (October-December). These definitions facilitate evaluation of seasonal contributions of $P$ and $S$ to totals for standard calendar years. For annual totals, $P$ ranges by $7.8 \mathrm{~cm}$ from $22.8 \mathrm{~cm}$ in 1978 to $30.6 \mathrm{~cm}$ in 1981, with a nearly equally high value in 1989 $(30.3 \mathrm{~cm})$. The corresponding extremes of $P-E$ are 12.5 (1978) and $20.3 \mathrm{~cm}$ (1981). Hence, inter-annual variability in $P$, while substantial, is not outstandingly large, as is evident from the fairly small coefficient of deviation (the standard deviation divided by the mean) of 0.11 . There is some suggestion of a multi-year cycle in $P$, with higher values in the mid-1970s and the early and late 1980s, which needs to be tested with a longer record.

$P$ for winter, spring and summer is more variable, with coefficients of deviation of $0.14,0.17$ and 0.16 , respectively, as compared to 0.08 for autumn. While we reiterate that our reconstructed $P$ values will contain some error due to the use of climatological $E$, ranking the results for each season reveals that the fairly modest variability in annual $P$ results from a tendency in many years for a relatively large $P$ in one season to be offset by relatively small $P$ in another. For example, while the high $P$ in spring $1977(6.9 \mathrm{~cm}$, second highest $)$ acted to offset low $P$ in winter $(2.9 \mathrm{~cm}$, lowest $)$, the large value in the autumn of $1991(9.2 \mathrm{~cm}$, second highest) was similarly offset by a small $P$ in winter $(3.5 \mathrm{~cm}$, third lowest). On this basis, 1981 and 1989 are unusual in that each year was represented by $P$ which for three seasons ranked among the five highest. By contrast, 1978 is unusual in showing small $P$ for three seasons. Turning to snowfall w.e., 1986 has the highest annual total $(21.0 \mathrm{~cm})$ and 1990 the lowest $(17.4 \mathrm{~cm})$. The variability in annual snowfall is less than for precipitation, as is evident by the smaller coefficient of deviation (0.09), but is again larger for individual seasons, especially for summer $(0.25)$.

\section{c. Girculation controls}

To place precipitation variations in the context of atmospheric circulation, we identified for each season the three years with the highest and lowest $P$. Composite means of 500 mbar height were then constructed for each three-season sub-set, using twice-daily U.S. National Meteorological Center (NMC) data in the octagonal grid format. Figure 5 shows fields of the high-precipitation composite and the high- minus low-precipitation composite difference for winter. The most notable feature is the large negative composite differences extending from south of Iceland into the central Arctic Ocean (i.e. lower heights for the high composite), maximized near the North Pole and Iceland. Results for the other seasons (not shown) are qualitatively similar, but with the negative differences for spring not extending to Iceland. As the high and low composite fields for all seasons exhibit essentially opposing anomaly patterns, the difference fields are not dominated by anomalies in one composite or the other. Results using $850 \mathrm{mbar}$ height and sea-level pressure (SLP) are similar.

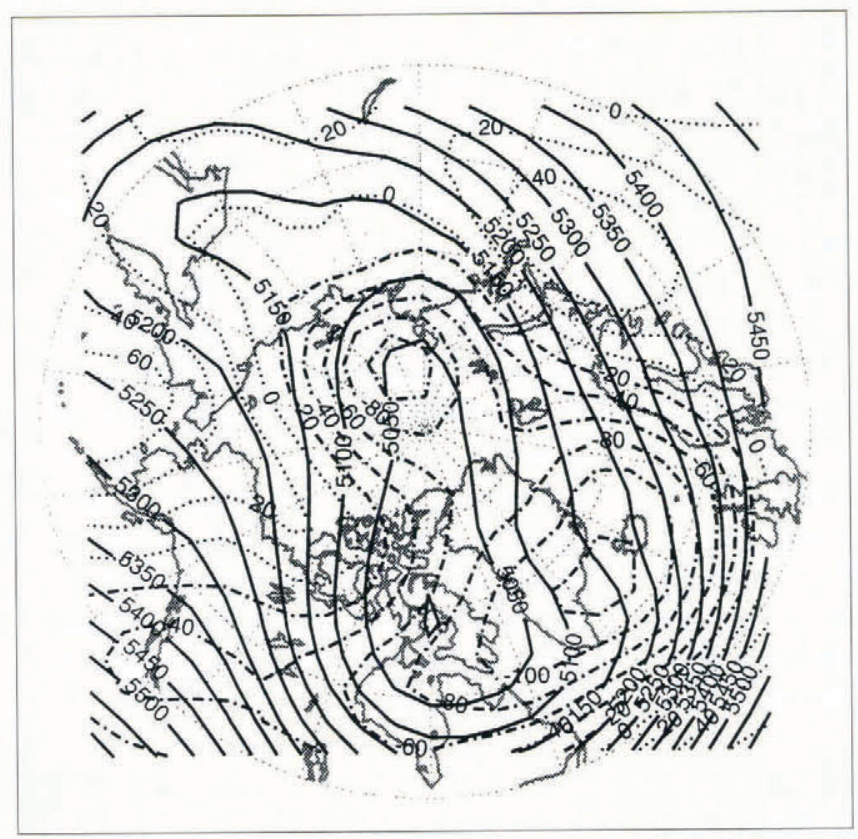

Fig. 5. Winter mean 500 mbar geopotential height field (m) for the high-precipitation composite (solid contours) and the high minus low composite height difference (dashed-dot and dotted contours for negative and positive differences, respectively). Positive differences mean higher 500 mbar heights for the high-precipitation composite.

The long-term (1974-91) mean winter 500 mbar pattern is dominated by a pronounced trough extending from south of Greenland into Baffin Bay (the northern extension of the eastern North American trough), an intervening weak ridge over northern Europe, a strong trough over Eurasia (the northern extension of the East Asian trough), and a strong ridge over western Canada and Alaska (the northern extension of the western North American ridge). The summer mean also contains these features, but with a weaker and more zonal circulation. In showing stronger troughs over the Atlantic and Eurasian sectors for the high composites, Figure 5 suggests that high winter $P$ is favored by amplification of the climatological circulation pattern and, from the similarity of the composite differences, a more "winter- 
type" circulation in the other seasons, and vice versa for low $P$. Snowfall extremes for winter and autumn occur for the same years as the precipitation extremes, but this is not true of spring and summer, reflecting the temperature effect. For example, while summer precipitation in 1986 was the lowest of the 18 years $(6.5 \mathrm{~cm})$, the season actually had the fourth highest snowfall total $(3.1 \mathrm{~cm}$ w.e. $)$ due to low summer temperatures.

In terms of associated synoptic activity, Serreze and others (1993) show that winter cyclonic activity exhibits a broad frequency maximum extending from Iceland into the Kara Sea. This is a reflection of the primary North Atlantic cyclone track, which represents the combined population of systems migrating poleward from lower latitudes, as well as those generated or rejuvenated within the Arctic itself. Climatologically, the existence of the track is in accord with the position of the eastern North American trough. Cyclones also frequently track into Baffin Bay and Davis Strait, resulting in another cyclonefrequency maximum in this region. Figure 6 shows the winter high-precipitation minus low-precipitation composite difference field of counts of sea-level cyclone centers at NMC grid points, obtained by applying an automated cyclone-detection algorithm (Serreze and others, 1993) to twice-daily NMC SLP fields. The raw grid counts have been weighted to emphasize the cyclones with lower central SLP, which (as a general rule) are more intense. The weighting factor is 1.50 for central pressures $<980$ mbar, 1.25 for those from 980 to 990 mbar, 1.12 for those from 990 to $1000 \mathrm{mbar}$, and 1.00 for those $>1000$ mbar. As the area represented by an NMC grid increases with latitude, the counts have been normalized with respect to the $381 \mathrm{~km} \times 381 \mathrm{~km}$ grid area at $60^{\circ} \mathrm{N}$.

Anomaly patterns of weighted cyclone distributions for

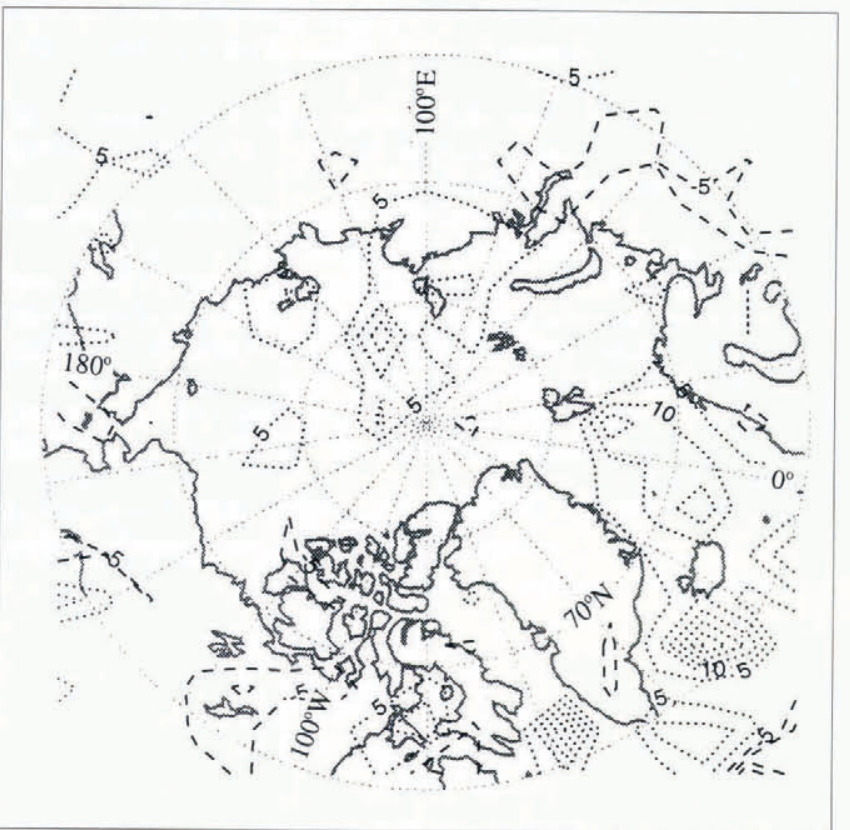

Fig. 6. Winter high-precipitation minus low-precipitation composite difference field of the numbers of sea-level cyclone centers weighted by central pressure (dotted contours, positive differences; dashed contours, negative differences; contour interval $=5$ ). Positive differences mean more cyclones for the high-precipitation composite. the high and low seasonal precipitation composites with respect to the 18 year means tend to be in opposition. The results in Figure 6 consequently indicate that, for winter, high $P$ and $S$ are associated with more frequent cyclonic activity over the Atlantic side of the Arctic, particularly south of Iceland, in the Norwegian Sea, north of the Laptev Sea and Davis Strait. Arguing for a stronger North Atlantic cyclone track, this again represents amplification of the normal winter pattern (Serreze and others, 1993). The spring and autumn composite difference patterns are qualitatively similar to winter. By contrast, while the summer high-precipitation composite shows modest increases of cyclonic activity over the Arctic Ocean, it is also characterized by a strong decrease over Eurasia and Canada. Typically, large increases in summer cyclone activity are found over these regions.

The conclusion that increased $P$ (and hence $P-E$ ) is associated with increased storm activity is not surprising. Recall, however, that variations in $P$ as examined here result from variations in the vapor-flux convergence (Equation (1)). Serreze and others (in press) show that the mean flux convergence, which is positive in all months, is most strongly driven by large poleward transient eddy vapor transports near the prime meridian, consistent with cyclonic activity along the North Atlantic track. The only region with mean equatorward transports at $70^{\circ} \mathrm{N}$ is the Canadian Arctic Archipelago, related to persistent northerly winds extending from the surface to at least 500 mbar, as can be inferred from the orientation of the height contours shown in Figure 5.

To place our results in this context, it is hence useful to examine changes in the patterns of the meridional vapor flux across $70^{\circ} \mathrm{N}$. Figure 7 shows, for winter at every $10^{\circ}$ longitude, the high-precipitation minus low-precipitation composite difference of the meridional flux as well as the high and low composite fluxes, expressed as anomalies with respect to the 18 year means. High winter $P$ is associated with positive composite differences peaking at about $10^{\circ}$ and $180^{\circ} \mathrm{E}$. While this in part reflects mean southerly winds (as inferred from the high composite geopotential-height contours at $500 \mathrm{mbar}$ and lower levels), implying a poleward time-mean flux, at least

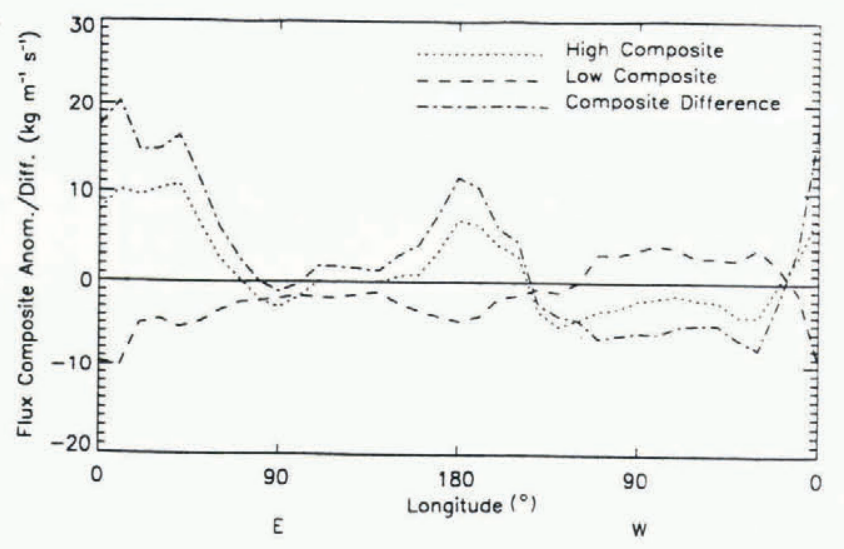

Fig. 7. Winter high minus low composile difference of the vertically integrated meridional water-vapor flux at $70^{\circ} \mathrm{N}$, with the corresponding high and low composites expressed as anomalies with respect to the 18 year record. Units are $\mathrm{kg} \mathrm{m}^{-1} \mathrm{~s}^{-1}$. 
near the prime meridian, the results are also consistent with strong transient eddy transports associated with increased cyclonic activity. Negative differences are found from about $30^{\circ}$ to $120^{\circ} \mathrm{W}$, over the Canadian Arctic Archipelago and Baffin Bay. For both composites, the fluxes over the Canadian Arctic Archipelago are negative, indicating that the high composites are actually associated with greater outflow from this region. Although the composite differences are negative in some areas, these are outweighed by the positive differences, resulting in a larger flux convergence for the high composites. Results for the remaining seasons (not shown) display different patterns, but share the common feature of above-average poleward fluxes over the Atlantic and Eurasian sectors of the Arctic.

\section{CONCLUSIONS}

Under the meridional atmospheric circulation patterns identified here, $P$ increases with respect to the long-term (1974-91) mean by $20 \%, 26 \%, 21 \%$ and $12 \%$ for winter, spring, summer and autumn, respectively. These changes also hold for winter and autumn snowfall. Of course, these results are only valid for the study domain north of $70^{\circ} \mathrm{N}$. Although our analysis provides only basin-wide averages, Gorshkov's (1983) maps do show a distinct precipitation maximum between Greenland and Scandinavia, along the North Atlantic cyclone track. It hence seems reasonable to infer that increases in $P$ and $S$ associated with the more meridional circulation would be most pronounced in this area. The greater issue of whether these "favorable" meridional circulation types will be more or less frequent under altered climatic states such as enhanced greenhouse warming remains to be addressed. Bromwich and others (1994) have assessed the ability of the NCAR CCMl to simulate present-day aspects of the Arctic circulation and hydrologic budget, and have found some large discrepancies from observations. A major problem is that the model under-represents storm activity along the North Atlantic track. Improving the simulation of this feature would appear to be a prerequisite for assessing the possible response of Arctic precipitation and snowfall to climate change.

\section{ACKNOWLEDGEMENTS}

This study was supported by NSF grants DPP-9214838, DPP-9113673 and ATM-9315351. We thank the Nat- ional Snow and Ice Data Center staff for computer support.

\section{REFERENCES}

Aagaard, K. and E. C. Carmack. 1989. The role of sea ice and other fresh waters in the Arctic circulation. 7. Geophys. Res., 94(C10), $14,485-14,498$.

Alestalo, M. 1983. The atmospheric water budget over Europe, In Street-Perrott, F. A., M. Beran and R. A. S. Ratcliffe, eds. Variations in the global water budget. Dordrecht, etc., D. Reidel Publishing Co, 6779.

Bromwich, D.H., R.Y. Tzeng and T.R. Parish. 1994. Simulation of the modern Arctic climate by the NCAR CCM1. J. Climate, 7 7), 1050-1069.

Chahine, M. T. 1992. GEWEX: the Global Energy and Water Cycle Experiment. EOS, $73(2), 913-914$.

Cressman, G. P. 1959. An operational objective analysis system. Mon. Weather Rev., 87, 367-374.

Goodison, B. E. and J. R. Metcalfe. 1981. An experiment to measure fresh snowfall water equivalent at Canadian climate stations. Eastern Snow Conference. Proceedings of the 1981 Annual Meeting, 110-112.

Gorshkov, S. G., ed. 1983. World ocean atlas, Vol. 3: Arctic Ocean. Oxford, etc., Pergamon Press.

Groisman, P. Y., V. V. Koknaeva, T. A. Belokrylova and T.R. Karl. 1991. Overcoming biases of precipitation: a history of the USSR experience. Bull. Am. Meteorol. Soc., 72, 1725-1733.

Kahl, J. D., M. C. Serreze, S. Shiotani, S. M. Skony and R. C. Schnell. 1992. In situ meteorological sounding archives for Arctic studies. Bull. Am. Meteorol. Soc, , 73(11), 1824-1830.

Korzun, V. I. 1977. Atlas miroroi vodnoi bolans (Atlas of world water balance). Leningrad, Gidrometeiozdat.

Maykut, G.A. and N. Untersteiner. 1971. Some results from a timedependent thermodynamic model of sea ice. J. Geophys. Res., 76 6), $1550-1575$.

Peixoto, J.P. and A.H. Oort. 1992. Physics of climate. New York, American Institute of Physics.

Robinson, D. A., M. C. Serreze, R. G. Barry, G. Scharfen and G. Kukla. 1992. Large-scale patterns and variability of snowmelt and parameterized surface albedo in the Arctic Basin. J. Climate., 5(10), 1109-1119.

Romanov, I. P. 1993. Atlas. Morphometric characteristics of ice and snow in the Arctic Basin. St. Petersburg, privately published.

Ross, B. and J. E. Walsh. 1987. A comparison of simulated and observed fluctuations in summertime Arctic surface albedo. J. Geophys. Res., 92 (12), 13,115-13,125.

Serreze, M. C., J.E. Box, R.G. Barry and J. E. Walsh. 1993. Characteristics of Arctic synoptic activity, 1952-1989. Meteorolog) and Atmospheric Physics, 51, 147-164.

Serreze, M. C., R. G. Barry and J. E. Walsh. In press. Atmospheric water vapor characteristics at $70^{\circ} \mathrm{N} .7$. Climate.

Vose, R. S. and 6 others. 1992. The global historical climatology network: longterm monthly temperature, precipitation, sea level pressure, and station pressure data. Oak Ridge, TN, Oak Ridge National Laboratory. Environmental Sciences Division. (Publication 3912.)

Walsh, J. E., X. Zhou, D. Portis and M. C. Serreze. 1994. Atmospheric contribution to hydrologic variations in the Arctic. Atmosphere-Ocean, 32(4), 733-755.

Woo, M. -k. R. Heron, P. Marsh and P. Steer. 1983. Comparison of weather station snowfall with winter snow accumulation in high Arctic basins. Atmosphere-Ocean, 21 (3), 312-325. 